\title{
Transcranial Sonography with Clinical and Demographic Characteristics to Predict Cognitive Impairment in PD: A Longitudinal Study
}

\section{Zhiguang Chen}

Capital Medical University

Wei Zhang

Capital Medical University

Wen He ( $\nabla$ hewen@bjtth.org )

Capital Medical University

\section{Yang Guang}

Capital Medical University

\section{Tengfei Yu}

Capital Medical University

Yue Du

Capital Medical University

Rui Li

Capital Medical University

\section{Research Article}

Keywords: Parkinson's Disease, Cognitive impairment, Substantia nigra hyper-echogenicity, Motor symptoms, Nonmotor symptoms, Transcranial sonography

Posted Date: November 3rd, 2021

DOI: https://doi.org/10.21203/rs.3.rs-1012951/v1

License: (c) This work is licensed under a Creative Commons Attribution 4.0 International License. Read Full License 


\section{Abstract \\ Background}

Parkinson's disease (PD) is a neurodegenerative disease second only to Alzheimer's disease and is clinically characterized by a series of motor and non-motor symptoms. The latter often appear before motor symptoms, while cognitive impairment mostly occurs within a few years after the diagnosis of PD. We Aimed to predict the risk factors of cognitive impairment in PD patients based on transcranial sonography, clinical symptoms, and demographic characteristics. Independent-sample $t$-test was used for continuous data, and chi-square test was used for countable data. According to the occurrence time of cognitive impairment $(\mathrm{Cl}), 172 \mathrm{PD}$ patients were divided into non- $\mathrm{Cl}(\mathrm{N}-\mathrm{Cl}$, $\mathrm{n}=48), \mathrm{Cl}$ at the first treatment $(\mathrm{F}-\mathrm{Cl}, \mathrm{n}=58)$, and $\mathrm{Cl}$ at the last treatment $(\mathrm{L}-\mathrm{Cl}, \mathrm{n}=66)$. The age of onset, first treatment and smoking history of $\mathrm{Cl}$ patients were significantly different from those with $\mathrm{N}-\mathrm{Cl}$. When age of first treatment $\geq 61$ years was considered the boundary value to diagnose $\mathrm{Cl}$, the sensitivity and specificity were $77.40 \%$ and $66.70 \%$, respectively. At the first treatment, there was significant difference in depression between $\mathrm{F}-\mathrm{Cl}$ and $\mathrm{N}-\mathrm{Cl}$. At the last treatment, the cumulative and new or aggravated hypomnesia of L-Cl was significantly more than that of $\mathrm{N}-\mathrm{Cl}$. There was significant difference in TCS grading between the first- and last treatment in L-Cl. Depression, sexual dysfunction, and olfactory dysfunction were independent risk factors for $\mathrm{Cl}$ during the last treatment, while memory impairment was an independent risk factor for $\mathrm{Cl}$ during the entire treatment. The sensitivity and specificity of predicting $\mathrm{Cl}$ in $\mathrm{PD}$ patients were $81.80 \%$ and $64.60 \%$, respectively. The older the age of onset and treatment of PD patients, the more likely they were to have $\mathrm{Cl}$. Hypomnesia, depression, sexual dysfunction, and olfactory dysfunction can be used as independent risk factors to predict $\mathrm{Cl}$ in PD patients.

\section{Introduction}

Parkinson's Disease (PD) is a progressive neurodegenerative disorder, which is characterized by bradykinesia, resting tremors, and rigidity. Autopsy is the gold standard for the diagnosis of PD, therefore the clinical diagnosis of PD is generally based on detailed and accurate clinical data ${ }^{1}$, which can be divided into clinically established PD and clinically probable PD. The former denotes that there are at least two supportive criteria in the absence of absolute exclusion criteria and red flags, while the latter refers to the presence of red flags balanced by supportive criteria without absolute exclusion criteria, and no more than two red flags ${ }^{2}$. Motor symptoms (MS) are the core feature of PD diagnosis, but non-motor symptoms (NMS) often appear before MS, and are considered as a new diagnostic classification, called prodromal PD ${ }^{3}$. NMS include mental symptoms (e.g., cognitive impairment, somnipathy, depression); autonomic symptoms (e.g., salivation, dysuria, constipation); and sensory abnormalities (e.g., pain and dysosmia) ${ }^{4}$. NMS are not only related to the early diagnosis of PD but also closely related to the prognosis. Malpetti et al. ${ }^{5}$ suggest that apathy can predict cognitive decline before the onset of dementia.

Dementia is mostly associated with diseases of the central nervous system (CNS) ${ }^{6}$, has varied etiology, and is characterized by mental decline and personality changes in varying degrees. In PD patients with a history of over 10 years, the incidence rate of dementia exceeds $75 \%$. Mild cognitive impairment $(\mathrm{MCl})$ refers to a transitional stage in PD patients who have cognitive impairment but do not develop PD dementia (PDD). It is also an important factor in the disability rate in $\mathrm{PD}^{7}$. Janvin et al. ${ }^{8}$ have shown that almost all patients with $\mathrm{MCl}$ will eventually meet the diagnostic criteria of PDD. Therefore, early identification of potential risk factors of $\mathrm{MCl}$ and prediction of PDD in PD patients are crucial for clinical diagnosis and treatment.

Substance nigra hyper-echogenicity (SNH) in transcranial sonography (TCS) is common in most PD patients, and has high sensitivity and specificity. However, SNH can still occur in normal subjects or in other CNS-related diseases such 
as Gaucher's disease ${ }^{9}$. At present, the mechanism of hyper-echogenicity is still unclear. Some studies have shown that the formation of hyper-echogenicity may be related to the deposition of ferritin ${ }^{9-12}$, which has been verified by quantitative susceptibility mapping ${ }^{13}$. Additionally, the hyper-echogenicity range is positively correlated with the extinction degree of the $\mathrm{SN}$ dopaminergic neurons, and the activation of microglia is related to the formation of hyperechogenicity ${ }^{14}$.

Many studies have reported the use of imaging examination such as positron-emission tomography (PET) and magnetic resonance imaging (MRI) combined with genetic analysis and cerebrospinal fluid (CSF) and clinical characteristics to predict the early diagnosis, progression, or risk factors of $\mathrm{Cl}$ in $\mathrm{PD}^{15-19}$. To our knowledge, there are few reports on the prediction of PD using TCS combined with clinical data, and the application is limited ${ }^{20-23}$. As a real-time, simple, economic, non-radioactive examination method, TCS plays an important role in the diagnosis and follow-up of PD patients ${ }^{24}$. However, it is affected by the temporal window and may not be applicable to all PD patients. Therefore, we aimed to use the results of at least two TCS imaging studies, change of clinical symptoms, and demographic data to evaluate and predict the possibility and risk factors of $\mathrm{Cl}$ and dementia in PD patients.

\section{Materials And Methods}

\section{Ethics declarations}

\section{Ethics approval and consent to participate}

The Ethics Committee of the Beijing Tiantan Hospital Affiliated to Capital Medical University (Beijing, China) approved the study protocol. The study was carried out according to the tenets of the Declaration of Helsinki. All patients provided oral or written informed consent to participate in our study.

\section{Data collection and patient information}

Data was collected from all inpatients admitted to the Ward of Dyskinesia and Cognitive Disorders, Beijing Tiantan Hospital Affiliated to Capital Medical University, from April 2019 to April 2021. In all, 988 of the 1,540 inpatients were excluded because of Parkinson's syndrome, essential tremor (ET), progressive supranuclear palsy (PSP), multiple system atrophy (MSA), vascular PD, and Alzheimer's disease. The remaining 552 patients were clinically diagnosed with PD. Of these patients, 335 had only one hospitalization experience. Of the remaining 217 patients, 18, 15, and 12 patients who had incomplete TCS results, incomplete clinical history, and a <6-month interval between two hospitalizations, respectively, were excluded. Finally, 172 eligible patients with PD were included in this study.

The inclusion criteria were as follows: (i) The clinical diagnosis was PD, (ii) the MS and NMS records were complete, (iii) TCS examination was completed during both hospitalizations, and the SN could be clearly displayed and graded (during the hospitalization, the time between TCS and hospitalization was no more than 2 weeks), and (iv) the interval time between two hospitalizations was $\geq 6$ months.

The exclusion criteria were as follows: (i) The clinical diagnosis was non-PD, (ii) The SN of TCS examination was not clear, and (iii) the clinical history was incomplete.

The process of the patient selection is shown in Figure 1.

\section{Clinical data collection}


In this study, we collected the data regarding PD patients' age, blood pressure, blood glucose, blood lipid, smoking history, alcohol consumption history, history related to head injury and carbon monoxide poisoning, and duration of disease. MS, NMS, and TCS at the time of first and last treatment were also recorded.

All subjects underwent a thorough neurological examination including the motor part of the Unified PD Rating Scale (UPDRS-III). The Mini Mental State Examination (MMSE) and Montreal Cognitive Assessment (MoCA) were used to screen for Cl. Pittsburgh Sleep Quality Index (PSQI) was used to evaluate sleep disorders, Hamilton Anxiety Scale (HAMA) was used to evaluate anxiety, Hamilton Depression Scale (HAMD) was used to evaluate depression, and the

Drooling Severity and Frequency Scale (DSFS) was used to evaluate salivation. Postural hypotension was evaluated by blood-pressure measurement in the supine position, $1 \mathrm{~min}, 3 \mathrm{~min}$, and $5 \mathrm{~min}$ after standing up. According to a patient's history and $>3$ failures on the 12-item smell identification test from Sniffin' Sticks was used to evaluate olfactory dysfunction. Brief Pain Inventory (BPI) was used to evaluate pain. Restless Legs Syndrome Severity Rating Scale (RLSRS) was used to evaluate restless legs syndrome (RLS).

In this study, we only determined whether these clinical symptoms appeared or worsened. According to the score of the last examination, the reduction or aggravation of the first clinical symptom was evaluated. The specific scoring results are not provided in this article.

\section{Transcranial sonography}

The patient was placed in the supine position with full exposure of the temporal window. A Philips (Canon Aplio i900) S5-1 MHz phased array probe was used for scanning, and the depth and brightness of the instrument were adjusted according to the patient's condition. Two sonographers with at least 5 years' experience in the diagnosis of SN lesions performed the ultrasound examination, and the hyperechoic areas of SN were depicted and measured in a double-blind manner without knowing the patient's clinical diagnosis. The echo of SN was graded according to Bartova et al. ${ }^{25}$. The specific classification was as follows: Grade I: the same as that of the brainstem, Grade II: with scattered points and thin lines slightly stronger than the brainstem, Grade III: with patches of moderate echogenicity but weaker than the brain pool, Grade IV: with patches of hyper-echogenicity as the same as the brain pool, Grade V: with patches of hyperechogenicity stronger than the brain pool. Grades I and II were considered as normal SN, while grades III-V were considered $\mathrm{SNH}$.

\section{Data analysis}

Statistical analyses were performed using SPSS software (version 25.0, (IBM Corporation, Armonk, NY, USA). We analyzed the demographic and basic clinical information of 172 PD patients. Continuous data were expressed as mean \pm standard deviation (SD). Independent-samples $t$-test was used for the age of onset, age of first treatment, and duration of disease. The sex and ethnicity family history, smoking history, drinking history, hypertension, hyperlipidemia, diabetes, and history of head injury and carbon monoxide poisoning were analyzed by chi-square test. Furthermore, we used chi-square test to analyze the clinical symptoms of PD patients with and without $\mathrm{Cl}$ at the first treatment, the accumulated and new or aggravated clinical symptoms at the last treatment.

Cohen's kappa consistency test was used to evaluate the judgment and grading of hyperechoic results in the SN by two sonographers. Those parameters with $\mathrm{P}<0.1$ were included in the logistic regression analysis, and the ROC curve was established to analyze the diagnostic efficiency. Finally, the odds ratio (OR) was calculated for the clinical symptoms and ultrasonic signs of dementia and non-dementia in patients with $\mathrm{Cl}$.

\section{Results}




\section{Clinical demographic results}

The 172 PD patients were divided into three groups based on the time of appearance of $\mathrm{Cl}$ : $\mathrm{Cl}$ occurring at the first treatment $(\mathrm{F}-\mathrm{Cl}, \mathrm{n}=58), \mathrm{Cl}$ occurring at the last treatment $(\mathrm{L}-\mathrm{Cl}, \mathrm{n}=66)$, and no $\mathrm{Cl}$ during the entire duration of follow-up $(\mathrm{N}-\mathrm{Cl}, \mathrm{n}=48)$. In this study, the age of onset was equal to the age of first treatment minus the duration of disease. There was significant difference in the age of onset, age of first treatment, and smoking history between the $\mathrm{N}-\mathrm{Cl}$ and $\mathrm{Cl}$ groups ( $\mathrm{F}-\mathrm{Cl}$ and $\mathrm{L}-\mathrm{Cl})$, but no difference was noted between the $\mathrm{F}-\mathrm{Cl}$ and $\mathrm{L}-\mathrm{Cl}$ groups (Table 1).

We used single-factor ANOVA analysis for age of onset, age of first treatment, and duration of disease. The area under the ROC curve (AUC) of age of first treatment was the largest (Figure 2). When the age of first treatment $\geq 61$ years was considered as the threshold value for PD diagnosis in patients with $\mathrm{Cl}$, the sensitivity and specificity were $77.40 \%$ and $66.70 \%$, respectively.

\section{Comparison of MS and NMS among subgroups}

\subsection{Comparison of $\mathrm{F}-\mathrm{Cl}$ and $\mathrm{N}-\mathrm{Cl}$, and $\mathrm{Non}-\mathrm{FCl}(\mathrm{L}-\mathrm{Cl}$ and $\mathrm{N}-\mathrm{Cl})$ clinical symptoms at the first treatment}

We carried out detailed statistical analysis on the clinical symptoms of PD patients at the first treatment and compared the $\mathrm{MS}$ and $\mathrm{NMS}$ of $\mathrm{F}-\mathrm{Cl}$ and $\mathrm{N}-\mathrm{Cl}, \mathrm{F}-\mathrm{Cl}$ and Non-FCl (Which refers to PD patients without $\mathrm{Cl}$ at the first treatment, including: $\mathrm{L}-\mathrm{Cl}$ and $\mathrm{N}-\mathrm{Cl}$ ). As shown in Table 2, there was a significant difference in depression between $\mathrm{F}-\mathrm{Cl}$ and $\mathrm{N}-\mathrm{Cl}$, which shows that the depression is more common in patients with $\mathrm{Cl}$ at the first treatment than in those without $\mathrm{Cl}$ during treatments.

Upon comparing $\mathrm{F}-\mathrm{Cl}$ with $\mathrm{N}-\mathrm{Cl}$, the $\mathrm{P}$ values of depression and anxiety were 0.047 and 0.087 , respectively, which were included in the logistics regression analysis.

\subsection{Comparison of clinical symptoms at the first treatment and cumulative and newly added symptoms at the last treatment between $\mathrm{L}-\mathrm{Cl}$ and $\mathrm{N}-\mathrm{Cl}$}

We compared the clinical symptoms of $\mathrm{L}-\mathrm{Cl}$ and $\mathrm{N}-\mathrm{Cl}$ at the first treatment. There was a significant difference in depression and olfactory dysfunction between the $\mathrm{L}-\mathrm{Cl}$ and $\mathrm{N}-\mathrm{Cl}$ groups (Table 3). Accordingly, we analyzed the new or aggravated symptoms of $\mathrm{L}-\mathrm{Cl}$ and $\mathrm{N}-\mathrm{Cl}$ patients at the last treatment and compared the differences in the total clinical symptoms. The results suggest that there is a significant difference in total symptoms between $\mathrm{L}-\mathrm{Cl}$ and $\mathrm{N}-\mathrm{Cl}$ in hypomnesia and reduced computing power (RCP). New or aggravated hypomnesia is more common in L-Cl than in N$\mathrm{Cl}(\mathrm{P}=0.016)$.

Statistically significant clinical symptoms (depression, olfactory dysfunction, hypomnesia, $R C P$, all $P<0.05$ ) and sexual dysfunction and anxiety $(0.05 \leq \mathrm{P}<0.1)$ were included in the logistics regression analysis.

\section{Comparison of TCS results between the first- and last- examination}

TCS was performed in PD patients during the first and last hospitalization. In almost all patients, the midbrain area, hyperechoic area, and echo grading of the SN were recorded. Compared with the first TCS, the increased grade of SN in PD patients was significantly more than the decreased grading $(P=0.001)$ (Figure3, Table 4).

There was no statistically significant difference in the ultrasonic examination time interval among the three groups of PD patients. Interestingly, there was a difference in the midbrain area between the last and the first examination in patients with $\mathrm{F}-\mathrm{Cl}$, but not in patients with $\mathrm{L}-\mathrm{Cl}$ and $\mathrm{N}-\mathrm{LC}$. The grading of the last TCS examination of L-Cl was higher than that of the first $(P=0.023)$. 


\section{Logistics regression analysis}

The demographic differences of 172 patients with respect to age of onset, age of first treatment, and smoking history were statistically significant, which were included in the logistics regression analysis. Although the difference in the change of the midbrain area within the group at the first- and last examination of F-Cl was statistically significant, there were differences in the application of the midbrain area in our cross-sectional study. Therefore, it is difficult to consider the midbrain area as an index to measure the disease progress of patients. SNH is a relatively qualitative imaging index. As a typical ultrasound manifestation of PD patients, it can represent the value of TCS in PD examination. Therefore, we only included the different ultrasound grading of $\mathrm{SN}$ in the logistics regression analysis.

\subsection{Logistics regression analysis of the demographics and clinical symptoms of $\mathrm{F}-\mathrm{Cl}$ and $\mathrm{N}-\mathrm{Cl}$}

The results showed that the age of onset, age of first treatment, smoking history, anxiety, and depression were not independent risk factors for $\mathrm{Cl}$ in PD patients at the first treatment (Table 5).

The ROC was established according to the logistics regression analysis results of $\mathrm{F}-\mathrm{Cl}$ and $\mathrm{N}-\mathrm{Cl}$ (Fig. 4), and the AUC was 0.770 . The sensitivity and specificity of identifying PD patients with $\mathrm{Cl}$ at the first treatment were $83.10 \%$ and $68.70 \%$, respectively.

\subsection{Logistics regression analysis of demographics, first clinical symptoms, and first ultrasound grading of L-Cl and N-Cl}

There were statistically significant differences in depression, sexual dysfunction, and olfactory dysfunction between L$\mathrm{Cl}$ and $\mathrm{N}-\mathrm{Cl}$ patients, indicating that these signs are independent risk factors in identifying PD patients without $\mathrm{Cl}$ at the first treatment and whether $\mathrm{Cl}$ will occur later (Table 6).

The ROC was established according to the logistics regression analysis results of L-CI and N-Cl (Fig. 5), and the AUC was 0.793 . The sensitivity and specificity of predicting $\mathrm{Cl}$ in PD patients were $81.8 \%$ and $64.6 \%$, respectively.

\subsection{Logistics regression analysis of cumulative clinical symptoms, last ultrasound grading, and demographics of patients with $\mathrm{L}-\mathrm{Cl}$ and $\mathrm{N}-\mathrm{Cl}$ at the last treatment}

Only hypomnesia was an independent risk factor for $\mathrm{Cl}$ in PD patients, while the last ultrasound grading was not an independent risk factor (Table 7).

The ROC was established according to the logistics regression analysis results of $\mathrm{L}-\mathrm{Cl}$ and $\mathrm{N}-\mathrm{Cl}$ (Fig. 6), and the AUC was 0.783 . The sensitivity and specificity of identifying PD patients with cognitive impairment at the last treatment were $59.1 \%$ and $85.4 \%$, respectively.

\section{Risk factors of PDD in patients with cognitive impairment}

Although it is reported that patients with $\mathrm{Cl}$ will eventually meet the diagnostic criteria of dementia ${ }^{9}$, only some patients were finally diagnosed with PDD or dementia during the follow-up period in our study. Therefore, we analyzed the clinical and ultrasound odds ratio (OR) of PDD and non-PDD to identify the risk factors of dementia in patients with $\mathrm{Cl}$. An $O R=1$ indicates that this factor has no effect on the occurrence of disease, $O R>1$ indicates that the factor is a risk factor, $\mathrm{OR}<1$ indicates that the factor is a protective factor (Table 8).

In PD patients with $\mathrm{Cl}$, the risk of dementia increased 5.882 times with RCP. Moreover, rigidity and olfactory dysfunction are also risk factors for dementia, 2.091- and 1.987-times higher than in N-PDD patients, respectively. However, drinking history, somnipathy, and sexual dysfunction were protective factors for dementia in PD patients with $\mathrm{Cl}$. 


\section{Discussion}

Parkinson's disease is a common and complex neurological disease, with unclear pathogenesis. Dopaminergic neuron death in the SN pars compacta is an important pathological change in $\mathrm{PD}^{26,27}$. The resultant dopamine deficiency within the basal ganglia leads to a movement disorder, which is characterized by classical parkinsonian MS. The MS and NMS in patients with PD are heterogeneous, which prompted correct understanding of PD. NMS are closely related to the decline of quality of life in PD patients, and it may appear decades earlier than $\mathrm{MS}^{28,29}$. Some studies suggest that there are differences in NMS between men and women. Men are more likely to show more sexual dysfunction, forgetfulness, and dream re-activation, whereas females report more unexplained weight change and anxiety ${ }^{30}$. In this study, there was no significant difference in follow-up time among the three groups (interval time, $P=0.232$ ). Therefore, it can be considered that the difference of MS and NMS in the three groups was not related to the length of follow-up time.

In this study, we conducted a univariate analysis of demographic characteristics. According to the statistical results, it was clear that there are differences in the age of onset, age of first treatment, and smoking history between patients with $\mathrm{Cl}$ and $\mathrm{N}-\mathrm{Cl}$. The older the age of PD onset, the greater the likelihood of developing $\mathrm{Cl}$. When the age of first treatment in PD patients was taken as $\geq 61$ years, the sensitivity and specificity of diagnosing $\mathrm{Cl}$ were $77.40 \%$ and $66.70 \%$, respectively. At present, studies have confirmed that age is the most relevant predictor of $\mathrm{Cl}$ in PD patients, and our results are consistent with this report ${ }^{31,32}$. Smoking history is also related to the occurrence of $\mathrm{Cl}$. Our research results showed that the overall comparison difference among the three groups of patients was statistically significant. In the pairwise comparison, only $\mathrm{N}-\mathrm{Cl}$ and L-Cl had significant differences in smoking history, indicating that the smoking history of PD patients with $\mathrm{Cl}$ in the last treatment was higher than that of $\mathrm{N}-\mathrm{Cl}$ patients. Current studies suggest that smokers have a lower risk of PD, which may be related to some yet unknown effects of tobacco leaves ${ }^{33-}$ ${ }^{35}$. Smoking history is a risk factor for $\mathrm{Cl}$ in $\mathrm{PD}$ patients, and the relative risk ratio is approximately $1.31^{36}$, which is consistent with our research. Therefore, it appears that smokers have a low risk of PD, but PD patients with smoking history are more prone to $\mathrm{Cl}$ than PD patients without smoking history. When analyzing the OR of dementia in PD patients, it was found that smoking history was a protective factor for dementia in patients with $\mathrm{Cl}(\mathrm{OR}<1)$. Therefore, smoking history plays a protective, dangerous, and protective role in the onset of Parkinson's disease, $\mathrm{Cl}$, and dementia.

In this study, we made a detailed statistical analysis of MS and NMS in PD patients. There was significant difference in depression between $\mathrm{N}-\mathrm{Cl}$ and $\mathrm{F}-\mathrm{Cl}$ at the first treatment, indicating that PD patients with $\mathrm{Cl}$ were more likely to be accompanied by depression. Depression is very common in PD. Many studies have shown that depression, apathy, and $\mathrm{Cl}$ have a serious impact on the quality of life of PD patients ${ }^{37-41}$. However, in the results of logistics regression analysis, depression is not an independent risk factor for $\mathrm{Cl}$ in $\mathrm{PD}$ patients at the first treatment. When analyzing the clinical symptoms of $\mathrm{L}-\mathrm{Cl}$ and $\mathrm{N}-\mathrm{Cl}$ at the first treatment, we obtained the same results. The difference in depression between the two groups was statistically significant. Therefore, PD patients with depression are more prone to $\mathrm{Cl}$, thus, early intervention for PD patients with depression is of clinical value $\mathrm{e}^{42,43}$. In this study, the proportion of PD patients with $\mathrm{Cl}$ accompanied by depression at the first treatment was $36.21 \%(21 / 58)$, which was similar to the results of a previous meta-analysis $(25 \rrbracket 40 \%)^{44}$. In our study, there were significant differences between olfactory dysfunction at the first treatment of $\mathrm{N}-\mathrm{Cl}$ and $\mathrm{L}-\mathrm{Cl}$, and the results of logistic regression analysis showed that olfactory dysfunction, depression, and sexual dysfunction were independent risk factors for $\mathrm{Cl}$ in PD patients. Logistic regression analysis showed that the sensitivity and specificity of predicting cognitive impairment in PD patients were $81.80 \%$ and $64.60 \%$, respectively. The sensitivity of identifying PD patients with $\mathrm{Cl}$ at the first treatment was $83.10 \%$, and the specificity of identifying PD patients with $\mathrm{Cl}$ at the last treatment was $85.40 \%$. Olfactory dysfunction often occurs decades before MS and Cl. It is considered a clinical marker in the early stage of CNS disorders and is related to disease progression 
and $\mathrm{Cl}^{45}$. There are relatively few studies on sexual dysfunction in PD. At present, studies have reported that PD patients are more likely to suffer from sexual dysfunction than normal people ${ }^{46,47}$. In our study, we found that sexual dysfunction is an independent predictor of $\mathrm{N}-\mathrm{Cl}$ in PD patients, and sexual dysfunction is a protective factor for dementia in patients with cognitive impairment $(\mathrm{OR}=0.350)$. Therefore, we can speculate that sexual dysfunction plays a protective role in the progression of $\mathrm{PD}$, which may be related to the level of sex hormones. Estrogen is accumulated in PD patients with sexual dysfunction, and estrogen is considered to have neuroprotective effects ${ }^{48,49}$.

In this study, there was a difference in the cumulative frequency of RCP and hypomnesis between $\mathrm{L}-\mathrm{Cl}$ and $\mathrm{N}-\mathrm{Cl}$ at the last treatment, but only hypomnesis was an independent risk factor for $\mathrm{Cl}$ at the last treatment. In the last treatment of $\mathrm{L}-\mathrm{Cl}$ patients, only new or aggravated hypomnesis was statistically significant compared with $\mathrm{N}-\mathrm{Cl}$, indicating that PD patients with hypomnesis are more prone to $\mathrm{Cl}$ than those without hypomnesis. Moreover, hypomnesis is also a risk factor for dementia in patients with $\mathrm{Cl}(\mathrm{OR}=1.216)$.

Cognitive impairment is the most common and important NMS. The timing, characteristics, and rate of $\mathrm{Cl}$ vary greatly among individuals with PD. Moreover, several studies have shown that $\mathrm{Cl}$ is a precursor of PDD ${ }^{50-52}$. Therefore, it is important to identify which clinical and imaging manifestations may be related to the occurrence of dementia in PD patients with $\mathrm{Cl}$. We used OR to identify the risk factors of dementia in patients with $\mathrm{Cl}$. As OR>1 indicates that the sign is a risk factor for dementia in patients with $\mathrm{Cl}$. Whereas, as $\mathrm{OR}<1$ is defined as a protective factor. In our study, male sex, hyperlipidemia, hypertension, diabetes, rigidity, hypomnesis, RCP, anxiety, apathy, constipation, postural hypotension, salivation, olfactory dysfunction, RLS, and SNH were risk factors for PDD in patients with $\mathrm{Cl}$.

\section{Limitations}

First, almost all patients were hospitalized when their clinical symptoms became obvious or affected their quality of life. The duration of this precursor stage was different, resulting in some patients' clinical symptoms or treatment measures deviating from the real situation in the process of history taking. Although there was no significant difference in the follow-up time among the three groups, the follow-up time of each patient was different. The difference between individuals cannot be ignored. Some patients with short follow-up period may not have $\mathrm{Cl}$ or dementia at present, but this does not mean that these patients will not develop $\mathrm{Cl}$ or dementia in the future. Second, the compliance of patients was poor. Many patients were not treated according to the doctor's order during discharge, which makes us unable to accurately evaluate the therapeutic effect of drugs. Therefore, the impact of drug use on whether PD patients have $\mathrm{Cl}$ or PDD needs further long-term follow-up in a larger sample size. Finally, this study is a retrospective analysis, hence, selection bias cannot be avoided.

\section{Expectation}

As a real-time, simple, and noninvasive imaging technique, ultrasonography has advantages in the diagnosis and follow-up of PD patients. Moreover, TCS can not only directly display the SNH but also display brainstem raphe ${ }^{53}$, and abnormal reduction in brainstem raphe echogenicity is associated with depression and anxiety ${ }^{54}$. However, the red nucleus and SN cannot be accurately distinguished on TCS images, therefore it is impossible to accurately locate the hyperechogenic site. In future research, fusion imaging with MRI and TCS ${ }^{55,56}$ can be used to locate and identify the hyperechogenic site and further analyze the relationship between SNH and MS and NMS.

\section{Conclusions}

Patients with PD with $\mathrm{Cl}$ are older and often have smoking history, which is a protective factor for the onset of PD and dementia. Hypomnesis, depression, sexual dysfunction, and olfactory dysfunction are independent risk factors for $\mathrm{Cl}$ in 
PD patients. The sensitivity and specificity of predicting $\mathrm{Cl}$ in PD patients by logistic regression analysis was $81.8 \%$ and $64.6 \%$, respectively. The incidence of dementia in $\mathrm{Cl}$ patients with RCP, olfactory dysfunction, nonchalance, and SNH was 5.882-, 1.987-, 1.390-, and 1.208-times higher than that in patients without related manifestations.

\section{Abbreviations}

PD: Parkinson's disease

MS: Motor symptoms

NMS: Non-motor symptoms

TCS: Transcranial sonography

MCl: Mild cognitive impairment

PET: Positron-emission tomography

MRI: Magnetic resonance imaging

SN: Substantia nigra

SNH: Substantia nigra hyper-echogenicity

N-Cl: Non-cognitive impairment

F-Cl: First-cognitive impairment

L-Cl: Last-cognitive impairment

PDD: Parkinson's disease dementia

RLS: Restless legs syndrome

RCP: Reduced computing power

ET: Essential tremor

PSP: Progressive supranuclear palsy

MSA: Multiple system atrophy

CNS: Central nervous system

OR: Odds ratio

ROC: Receiver operating characteristic curve

AUC: Area under the ROC curve

SD: Standard deviation

\section{Declarations}




\section{Author Contributions:}

Conception and design of the study: Wen He, Wei Zhang.

Generation of data: Yang Guang, Tengfei Yu, Zhiguang Chen.

Collection, assembly, analysis of data: Zhiguang Chen.

Drafting of the manuscript: Zhiguang Chen, Wei Zhang.

Approval of the final version of the manuscript: Wen He.

All authors have read and approved the final manuscript.

\section{Funding}

None received.

\section{Ethics declarations}

\section{Ethics approval and consent to participate}

The Ethics Committee of the Beijing Tiantan Hospital Affiliated to Capital Medical University (Beijing, China) approved the study protocol.

\section{Consent for publication}

Publication is approved by all authors and tacitly or explicitly by the responsible authorities where the work was carried out.

\section{Competing interests}

The author(s) declare no competing interests.

\section{Data Availability}

The datasets generated during and/or analyzed during the current study are available from the corresponding author upon reasonable request.

\section{References}

1. Heinzel S, Berg D, Gasser T, et al. MDS Task Force on the Definition of Parkinson's Disease. Update of the MDS research criteria for prodromal Parkinson's disease. Mov Disord. 2019, 34:1464-1470.

2. Postuma RB, Berg D, Stern M, et al. MDS clinical diagnostic criteria for Parkinson's disease. Mov Disord. 2015, 30:1591-601.

3. Pont-Sunyer C, Hotter A, Gaig C, et al. The onset of nonmotor symptoms in Parkinson's disease (the ONSET PD study). Mov Disord. 2015, 30:229-37.

4. Jankovic J. Parkinson's disease: clinical features and diagnosis. J Neurol Neurosurg Psychiatry. 2008, 79:368-76.

5. Malpetti M, Jones PS, Tsvetanov KA, et al. Apathy in presymptomatic genetic frontotemporal dementia predicts cognitive decline and is driven by structural brain changes. Alzheimers Dement. 2021, 17:969-983. 
6. Gale SA, Acar D, Daffner KR. Dementia. Am J Med. 2018, 131:1161-1169.

7. Coelho M, Marti MJ, Sampaio C, et al. Dementia and severity of parkinsonism determines the handicap of patients in late-stage Parkinson's disease: the Barcelona-Lisbon cohort. Eur J Neurol. 2015, 22:305-12.

8. Janvin CC, Larsen JP, Aarsland D, et al. Subtypes of mild cognitive impairment in Parkinson's disease: progression to dementia. Mov Disord. 2006, 21:1343-9.

9. Böttcher T, Rolfs A, Meyer B, et al. Clinical, genetic, and brain sonographic features related to Parkinson's disease in Gaucher disease. J Neurol. 2013, 260:2523-31.

10. Berg D. Hyperechogenicity of the substantia nigra: pitfalls in assessment and specificity for Parkinson's disease. J Neural Transm (Vienna). 2011, 118:453-61.

11. Walter U, Školoudík D. Transcranial sonography (TCS) of brain parenchyma in movement disorders: quality standards, diagnostic applications and novel technologies. Ultraschall Med. 2014, 35:322-31.

12. Wang JY, Zhuang QQ, Zhu LB, et al. Meta-analysis of brain iron levels of Parkinson's disease patients determined by postmortem and MRI measurements. Sci Rep. 2016, 96:36669.

13. Ahmadi SA, Bötzel K, Levin J, et al. Analyzing the co-localization of substantia nigra hyper-echogenicities and iron accumulation in Parkinson's disease: A multi-modal atlas study with transcranial ultrasound and MRI. Neuroimage Clin. 2020, 26:102185.

14. Zhang S, Tao K, Wang J, et al. Substantia Nigra Hyperechogenicity Reflects the Progression of Dopaminergic Neurodegeneration in 6-OHDA Rat Model of Parkinson's Disease. Front Cell Neurosci. 2020, 4:216.

15. Schulz J, Pagano G, Fernández Bonfante JA, et al. Nucleus basalis of Meynert degeneration precedes and predicts cognitive impairment in Parkinson's disease. Brain. 2018, 141:1501-1516.

16. Lanskey JH, McColgan P, Schrag AE, et al. Can neuroimaging predict dementia in Parkinson's disease? Brain. 2018, 141:2545-2560.

17. Schrag A, Siddiqui UF, Anastasiou Z, et al. Clinical variables and biomarkers in prediction of cognitive impairment in patients with newly diagnosed Parkinson's disease: a cohort study. Lancet Neurol. 2017, 16:66-75.

18. Bi XA, Hu X, Xie Y, Wu H. A novel CERNNE approach for predicting Parkinson's Disease-associated genes and brain regions based on multimodal imaging genetics data. Med Image Anal. 2021, 67:101830.

19. Chahine LM, Siderowf A, Barnes J, et al. The Parkinson's Progression Markers Initiative. Predicting Progression in Parkinson's Disease Using Baseline and 1-Year Change Measures. J Parkinsons Dis. 2019, 9:665-679.

20. Mahlknecht P, Kiechl S, Stockner H et al. Predictors for mild parkinsonian signs: a prospective population-based study. Parkinsonism Relat Disord. 2015, 21:321-4.

21. Behnke S, Schröder U, Berg D. Transcranial sonography in the premotor diagnosis of Parkinson's disease. Int Rev Neurobiol. 2010, 90:93-106.

22. Tunc S, Graf J, Tadic V, et al. A population-based study on combined markers for early Parkinson's disease. Mov Disord. 2015, 30:531-7.

23. Walter U. Substantia nigra hyperechogenicity is a risk marker of Parkinson's disease: no. J Neural Transm (Vienna). 2011, 118:607-12.

24. Berg D, Godau J, Walter U. Transcranial sonography in movement disorders. Lancet Neurol. 2008, 7:1044-55.

25. Bartova P, Skoloudik D, Bar M, et al. Transcranial sonography in movement disorders. Biomed Pap Med Fac Univ Palacky Olomouc Czech Repub. 2008, 152:251-8.

26. Surmeier DJ. Determinants of dopaminergic neuron loss in Parkinson's disease. FEBS J. 2018, 285:3657-3668.

27. Cacabelos R. Parkinson's Disease: From Pathogenesis to Pharmacogenomics. Int J Mol Sci. 2017, 18:551.

Page $11 / 26$ 
28. Kalia LV, Lang AE. Parkinson's disease. Lancet. 2015, 386:896-912.

29. Marinus J, Zhu K, Marras C, et al. Risk factors for non-motor symptoms in Parkinson's disease. Lancet Neurol. 2018, 17:559-568.

30. Durcan R, Wiblin L, Lawson RA, et al. ICICLE-PD Study Group. Prevalence and duration of non-motor symptoms in prodromal Parkinson's disease. Eur J Neurol. 2019, 26:979-985.

31. Zhu K, van Hilten JJ, Marinus J. Predictors of dementia in Parkinson's disease, findings from a 5-year prospective study using the SCOPA-COG. Parkinsonism Relat Disord. 2014, 20:980-5.

32. Williams-Gray CH, Mason SL, Evans JR, et al. The CamPaIGN study of Parkinson's disease: 10-year outlook in an incident population-based cohort. J Neurol Neurosurg Psychiatry. 2013, 84:1258-64.

33. Ascherio A, Schwarzschild MA. The epidemiology of Parkinson's disease: risk factors and prevention. Lancet Neurol. 2016, 15:1257-1272.

34. Breckenridge CB, Berry C, Chang ET, et al. Association between Parkinson's Disease and Cigarette Smoking, Rural Living, Well-Water Consumption, Farming and Pesticide Use: Systematic Review and Meta-Analysis. PLoS One. 2016, 11:e0151841.

35. Hopfner F, Höglinger GU, Kuhlenbäumer G, et al. $\beta$-adrenoreceptors and the risk of Parkinson's disease. Lancet Neurol. 2020, 19:247-254.

36. Guo Y, Xu W, Liu FT, et al. Modifiable risk factors for cognitive impairment in Parkinson's disease: A systematic review and meta-analysis of prospective cohort studies. Mov Disord. 2019, 34:876-883.

37. Marsh L. Depression and Parkinson's disease: current knowledge. Curr Neurol Neurosci Rep. 2013, 13:409.

38. Pagonabarraga J, Kulisevsky J. Apathy in Parkinson's Disease. Int Rev Neurobiol. 2017, 133:657-678.

39. Pagonabarraga J, Kulisevsky J, Strafella AP, et al. Apathy in Parkinson's disease: clinical features, neural substrates, diagnosis, and treatment. Lancet Neurol. 2015, 14:518-31.

40. Chaudhuri KR, Healy DG, Schapira AH.National Institute for Clinical Excellence. Non-motor symptoms of Parkinson's disease: diagnosis and management. Lancet Neurol. 2006, 5:235-45.

41. Broen MP, Narayen NE, Kuijf ML, et al.Prevalence of anxiety in Parkinson's disease: A systematic review and metaanalysis. Mov Disord. 2016, 31:1125-33.

42. Morimoto SS, Kanellopoulos D, Manning KJ, et al. Diagnosis and treatment of depression and cognitive impairment in late life. Ann N Y Acad Sci. 2015, 1345:36-46.

43. Gregory E, Torres IJ, Ge R, et al. Predictors of cognitive impairment in treatment-resistant depression. J Affect Disord. 2020, 274:593-601.

44. Ismail Z, Elbayoumi H, Fischer CE, et al. Prevalence of Depression in Patients With Mild Cognitive Impairment: A Systematic Review and Meta-analysis. JAMA Psychiatry. 2017, 74:58-67.

45. Marin C, Vilas D, Langdon C, et al. Olfactory Dysfunction in Neurodegenerative Diseases. Curr Allergy Asthma Rep. 2018, 15:42.

46. Zhao S, Wang J, Xie Q, et al. Parkinson's Disease Is Associated with Risk of Sexual Dysfunction in Men but Not in Women: A Systematic Review and Meta-Analysis. J Sex Med. 2019, 16:434-446.

47. Raciti L, De Cola MC, Ortelli P, et al. Sexual Dysfunction in Parkinson Disease: A Multicenter Italian Cross-sectional Study on a Still Overlooked Problem. J Sex Med. 2020, 17:1914-1925.

48. Saunders-Pullman R. Estrogens and Parkinson disease: neuroprotective, symptomatic, neither, or both? Endocrine. 2003, 21:81-7.

49. Cereda E, Cilia R, Klersy C, et al. Dementia in Parkinson's disease: Is male gender a risk factor? Parkinsonism Relat Disord. 2016, 26:67-72.

Page $12 / 26$ 
50. Emre M, Aarsland D, Brown R, et al. Clinical diagnostic criteria for dementia associated with Parkinson's disease. Mov Disord. 2007, 22:1689-707.

51. Litvan I, Goldman JG, Tröster Al, et al.Diagnostic criteria for mild cognitive impairment in Parkinson's disease: Movement Disorder Society Task Force guidelines. Mov Disord. 2012, 27:349-56.

52. Aarsland D, Creese B, Politis M, et al. Cognitive decline in Parkinson disease. Nat Rev Neurol. 2017, 13:217-231.

53. Zhang YC, Hu H, Luo WF, et al. Alteration of brainstem raphe measured by transcranial sonography in depression patients with or without Parkinson's disease. Neurol Sci. 2016, 37:45-50.

54. Bei HZ, Chen JP, Mao CJ, et al. Echogenicity Changes in Brainstem Raphe Detected by Transcranial Parenchymal Sonography and Clinical Characteristics in Parkinson's Disease. Front Neurol. 2020, 7:821.

55. Mašková J, Školoudík D, Burgetová A, et al. Comparison of transcranial sonography-magnetic resonance fusion imaging in Wilson's and early-onset Parkinson's diseases. Parkinsonism Relat Disord. 2016, 28:87-93.

56. Školoudík D, Mašková J, Dušek P, et al.Digitized Image Analysis of Insula Echogenicity Detected by TCS-MR Fusion Imaging in Wilson's and Early-Onset Parkinson's Diseases. Ultrasound Med Biol. 2020, 46:842-848.

\section{Tables}

Table 1. Demographic and clinical characteristics 


\begin{tabular}{|c|c|c|c|c|}
\hline & $\mathrm{N}-\mathrm{Cl}(\mathrm{n}=48)$ & $\mathrm{F}-\mathrm{Cl}(\mathrm{n}=58)$ & $\mathrm{L}-\mathrm{Cl}(\mathrm{n}=66)$ & $P$ \\
\hline Age of onset (years) & $14-77$ & $47-73$ & $32.5-75$ & $00.001^{\mathrm{a}}$ \\
\hline Mean \pm SD & $(53.20 \pm 11.29)$ & $(60.08 \pm 4.78)$ & $(59.82 \pm 10.28)$ & $0.862^{b}$ \\
\hline Age of first treatment & $29-78$ & $51-78$ & $33-80$ & {$\left[0.001^{a}\right.$} \\
\hline (years) Mean \pm SD & $(58.00 \pm 10.58)$ & $(64.53 \pm 4.36)$ & $(64.89 \pm 10.92)$ & $0.816^{b}$ \\
\hline \multicolumn{5}{|l|}{ Gender } \\
\hline Male & 34 & 35 & 46 & \multirow[t]{2}{*}{$0.429^{c}$} \\
\hline Female & 14 & 23 & 20 & \\
\hline \multicolumn{5}{|l|}{ Ethnicity } \\
\hline Han & 46 & 57 & 64 & \multirow[t]{2}{*}{$0.749^{e}$} \\
\hline Others & 2 & 1 & 2 & \\
\hline Family history & 2 & 4 & 3 & $0.787^{e}$ \\
\hline Smoking history & 9 & 15 & 29 & $0.010^{c} / 0.005^{c d}$ \\
\hline Drinking history & 10 & 4 & 9 & $0.105^{\mathrm{e}}$ \\
\hline Hypertension & 17 & 20 & 27 & $0.727^{c}$ \\
\hline Diabetes & 9 & 15 & 18 & $0.551^{\mathrm{c}}$ \\
\hline Hyperlipidemia & 10 & 11 & 14 & $0.948^{c}$ \\
\hline History of head injury & 3 & 5 & 6 & $0.849^{e}$ \\
\hline History of carbon monoxide poisoning & 6 & 5 & 11 & $0.407^{c}$ \\
\hline Duration of disease (years) & $0.5-20$ & $0.5-20(4.46 \pm 4.14)$ & $0.5-30$ & $0.763^{\mathrm{a}}$ \\
\hline Mean \pm SD & $(4.80 \pm 4.38)$ & & $(5.08 \pm 5.19)$ & \\
\hline
\end{tabular}
a: Single factor ANQVA analysis
b: Independent sample t test, comparison of $\mathrm{F}-\mathrm{Cl}$ and $\mathrm{L}-\mathrm{Cl}$
c: Chi square test
d: Comparison of $\mathrm{N}-\mathrm{Cl}$ and $\mathrm{L}-\mathrm{Cl}$
e: Continuity correction of chi square test

Table 2. Comparison of clinical symptoms of patients with F-Cl,

$\mathrm{N}-\mathrm{Cl}$ and $\mathrm{N}-\mathrm{FCl}$ at the first treatment 


\begin{tabular}{|c|c|c|c|c|c|c|}
\hline \multirow[t]{2}{*}{ clinical symptoms } & & $\mathrm{F}-\mathrm{Cl}$ & $\mathrm{N}-\mathrm{FCl}$ & $\mathrm{N}-\mathrm{Cl}$ & P1 & P2 \\
\hline & & $(n=58)$ & $(\mathrm{n}=114)$ & $(n=48)$ & & \\
\hline \multicolumn{7}{|l|}{ MS } \\
\hline & Bradykinesia & 58 & 114 & 48 & NA & NA \\
\hline & Rest tremor & 49 & 98 & 41 & $0.794^{c}$ & $0.894^{c}$ \\
\hline & Rigidity & 36 & 66 & 31 & $0.598^{c}$ & $0.789^{c}$ \\
\hline \multicolumn{7}{|l|}{ Mental symptoms } \\
\hline & Hypomnesia & 31 & 48 & 18 & $0.158^{c}$ & $0.101^{\mathrm{c}}$ \\
\hline & $\mathrm{RCP}$ & 5 & 12 & 3 & $0.692^{c}$ & $0.928^{e}$ \\
\hline & Cognitive impairment & 58 & 0 & 0 & NA & NA \\
\hline & Somnipathy & 14 & 17 & 7 & $0.137^{c}$ & $0.219^{c}$ \\
\hline & Anxiety & 25 & 41 & 13 & $0.363^{c}$ & $0.087^{c}$ \\
\hline & Depression & 21 & 36 & 9 & $0.542^{c}$ & $0.047^{c}$ \\
\hline & Apathy & 5 & 6 & 2 & $0.395^{c}$ & $0.599 \mathrm{e}$ \\
\hline \multicolumn{7}{|l|}{ Autonomic symptoms } \\
\hline & Constipation & 33 & 71 & 26 & $0.495^{c}$ & $0.778^{c}$ \\
\hline & Hyperhidrosis & 2 & 1 & 1 & $0.547^{\mathrm{e}}$ & $N A^{*}$ \\
\hline & Postural hypotension & 10 & 19 & 6 & $0.924^{c}$ & $0.497^{c}$ \\
\hline & Dysuria & 31 & 57 & 23 & $0.669^{c}$ & $0.571^{\mathrm{c}}$ \\
\hline & Salivation & 11 & 15 & 4 & $0.315^{c}$ & $0.199^{e}$ \\
\hline & Sexual dysfunction & 5 & 13 & 9 & $0.573^{c}$ & $0.125^{c}$ \\
\hline \multicolumn{7}{|l|}{ Sensory disturbance } \\
\hline & Olfactory dysfunction & 18 & 36 & 20 & $0.942^{c}$ & $0.256^{c}$ \\
\hline & Pain & 11 & 19 & 8 & $0.707^{c}$ & $0.759^{c}$ \\
\hline & Spasm & 0 & 1 & 1 & NA & NA \\
\hline & Numbness & 1 & 5 & 2 & $0.646^{e}$ & $0.868^{c}$ \\
\hline & RLS & 2 & 4 & 1 & $N A^{*}$ & $N A^{*}$ \\
\hline
\end{tabular}

NA: Not available

$N A^{*}$ : Not available after continuity correction, $\mathrm{P}=1$ 
P1: Comparison of MS and NMS between $\mathrm{F}-\mathrm{Cl}$ and $\mathrm{N}-\mathrm{FCl}$ at the first treatment

P2: Comparison of MS and NMS between $\mathrm{F}-\mathrm{Cl}$ and $\mathrm{N}-\mathrm{Cl}$ at the first treatment

RLS, Restless legs syndrome, MS, Motor symptoms, RCP, Reduced computing power

Table 3. Comparison of total, baseline and new or aggravated clinical symptoms between $\mathrm{L}-\mathrm{Cl}$ and $\mathrm{N}-\mathrm{Cl}$ 


\begin{tabular}{|c|c|c|c|c|c|c|c|}
\hline clinical symptoms & $\mathrm{L}-\mathrm{Cl}(\mathrm{n}=66)$ & $\begin{array}{l}\mathrm{N}-\mathrm{Cl} \\
(\mathrm{n}=48)\end{array}$ & $\mathrm{P} 1$ & $\begin{array}{l}\mathrm{L}-\mathrm{Cl} t / n \\
(n=66)\end{array}$ & $\begin{array}{l}\mathrm{N}-\mathrm{Cl} \mathrm{t} / \mathrm{n} \\
(\mathrm{n}=48)\end{array}$ & P2 & P3 \\
\hline \multicolumn{8}{|l|}{ MS } \\
\hline Bradykinesia & 66 & 48 & NA & $66 / 11$ & $48 / 10$ & NA & $0.571^{\mathrm{c}}$ \\
\hline Rest tremor & 57 & 41 & $0.886^{c}$ & $58 / 7$ & $43 / 9$ & $0.777^{c}$ & $0.123^{c}$ \\
\hline Rigidity & 35 & 31 & $0.217^{c}$ & $37 / 8$ & $34 / 10$ & $0.108^{c}$ & $0.208^{c}$ \\
\hline \multicolumn{8}{|l|}{ Mental symptoms } \\
\hline Hypomnesia & 30 & 18 & $0.396^{c}$ & $55 / 28$ & $26 / 10$ & $0.001^{c}$ & $0.016^{c}$ \\
\hline $\mathrm{RCP}$ & 9 & 3 & $0.337^{\mathrm{e}}$ & $22 / 13$ & $7 / 4$ & $0.023^{c}$ & $0.157^{c}$ \\
\hline Cognitive impairment & 0 & 0 & NA & $66 / 0$ & $0 / 0$ & NA & NA \\
\hline Somnipathy & 10 & 7 & $0.933^{c}$ & $23 / 13$ & $16 / 9$ & $0.866^{c}$ & $0.899^{c}$ \\
\hline Anxiety & 28 & 13 & $0.092^{c}$ & $33 / 7$ & $22 / 9$ & $0.660^{c}$ & $0.123^{c}$ \\
\hline Depression & 27 & 9 & $0.012^{c}$ & $35 / 10$ & $17 / 9$ & $0.062^{c}$ & $0.611^{c}$ \\
\hline Apathy & 4 & 2 & $0.982^{e}$ & $5 / 1$ & $2 / 0$ & $0.724^{\mathrm{e}}$ & NA \\
\hline \multicolumn{8}{|l|}{ Autonomic symptoms } \\
\hline Constipation & 45 & 26 & $0.127^{c}$ & $54 / 15$ & $35 / 9$ & $0.257^{c}$ & $0.607^{c}$ \\
\hline Hyperhidrosis & 0 & 1 & NA & $1 / 1$ & $2 / 1$ & 0.779 e & $N A^{*}$ \\
\hline Postural hypotension & 13 & 6 & $0.309^{c}$ & $25 / 13$ & $17 / 11$ & $0.788^{c}$ & $0.677^{c}$ \\
\hline Dysuria & 34 & 23 & $0.704^{c}$ & $44 / 11$ & $34 / 11$ & $0.637^{c}$ & $0.404^{c}$ \\
\hline Salivation & 11 & 4 & $0.308^{e}$ & $16 / 5$ & $8 / 4$ & $0.327^{c}$ & $N A^{*}$ \\
\hline Sexual dysfunction & 4 & 9 & $0.071^{\mathrm{e}}$ & $6 / 2$ & $10 / 1$ & $0.075^{c}$ & NA \\
\hline \multicolumn{8}{|l|}{ Sensory disturbance } \\
\hline Olfactory dysfunction & 16 & 20 & $0.048^{c}$ & $27 / 11$ & $26 / 6$ & $0.161^{c}$ & $0.537^{c}$ \\
\hline Pain & 11 & 8 & $N A^{*}$ & $16 / 6$ & $11 / 5$ & $0.896^{c}$ & $0.813^{c}$ \\
\hline Spasm & 0 & 1 & NA & $0 / 0$ & $1 / 0$ & NA & NA \\
\hline Numbness & 3 & 2 & $N A^{*}$ & $4 / 2$ & $2 / 0$ & $0.982^{e}$ & NA \\
\hline RLS & 3 & 1 & 0.849 e & $3 / 0$ & $1 / 0$ & $0.873^{e}$ & NA \\
\hline
\end{tabular}

P1: Comparison of MS and NMS between $\mathrm{L}-\mathrm{Cl}$ and $\mathrm{N}-\mathrm{Cl}$ at the first treatment

P2: Comparison of total clinical symptoms at the last treatment between $\mathrm{L}-\mathrm{Cl}$ and $\mathrm{N}-\mathrm{Cl}$ 
P3: Comparison of newly increased or aggravated clinical symptoms between $\mathrm{L}-\mathrm{Cl}$ and $\mathrm{N}-\mathrm{Cl}$ at the last treatment $\mathrm{t} / \mathrm{n}$, total/ new or aggravated,

Table 4. Comparison of first and Last TCS results

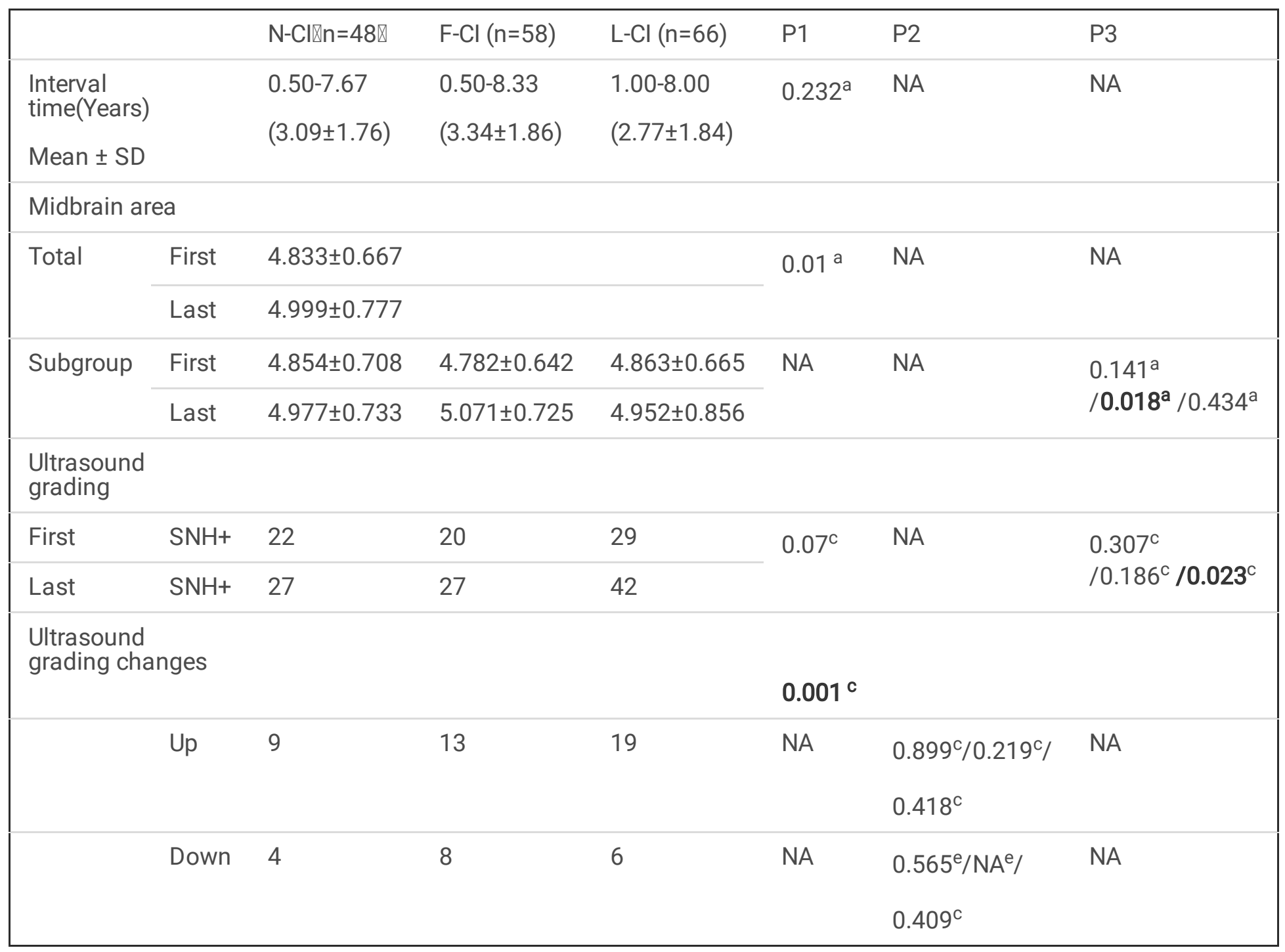

P1: Overall comparison among the three groups

P2: The comparison between groups, from left to right was N-Cl \& F-Cl, N-Cl \& L-Cl and F-Cl \& L-Cl.

P3: The difference between the first and last ultrasonic signs in each group, from left to right was $\mathrm{N}-\mathrm{Cl}, \mathrm{F}-\mathrm{Cl}$ and $\mathrm{L}-\mathrm{Cl}$. Interval time, the interval between two ultrasound examinations

Table 5. Logistics regression analysis results of clinical and demographic of $\mathrm{F}-\mathrm{Cl}$ and $\mathrm{N}-\mathrm{Cl}$ 


\begin{tabular}{|llllllll|}
\hline & $\begin{array}{l}\text { Regression } \\
\text { coefficient }\end{array}$ & $\begin{array}{l}\text { Standard } \\
\text { error }\end{array}$ & $\begin{array}{l}\text { Wald } \\
\text { Value }\end{array}$ & $P$ Value & OR & \multicolumn{2}{l|}{$95 \% \mathrm{Cl}^{\star}$} \\
\hline Age of onset & 0.070 & 0.054 & 1.705 & 0.192 & 1.073 & 0.965 & 1.192 \\
\hline $\begin{array}{l}\text { Age of first } \\
\text { treatment }\end{array}$ & 0.057 & 0.056 & 1.030 & 0.310 & 1.058 & 0.949 & 1.181 \\
\hline Smoking history & -1.016 & 0.551 & 3.400 & 0.065 & 0.362 & 0.123 & 1.066 \\
\hline Anxiety & 0.491 & 0.520 & 0.891 & 0.345 & 1.634 & 0.590 & 4.530 \\
\hline Depression & 0.365 & 0.551 & 0.438 & 0.508 & 1.441 & 0.489 & 4.245 \\
\hline
\end{tabular}

$\mathrm{Cl}^{\star}$, confidence interval

Table 6. Logistics regression analysis of clinical and ultrasonic signs at the first treatment

of $\mathrm{L}-\mathrm{Cl}$ and $\mathrm{N}-\mathrm{Cl}$

\begin{tabular}{|lllllllll|}
\hline & $\begin{array}{l}\text { Regression } \\
\text { coefficient }\end{array}$ & $\begin{array}{l}\text { Standard } \\
\text { error }\end{array}$ & $\begin{array}{l}\text { Wald } \\
\text { Value }\end{array}$ & $\begin{array}{l}P \\
\text { Value }\end{array}$ & OR & \multicolumn{2}{l|}{$95 \% \mathrm{Cl}^{*}$} \\
\hline Age of onset & 0.036 & 0.047 & 0.601 & 0.438 & 1.037 & 0.946 & 1.136 \\
\hline Age of first treatment & 0.024 & 0.048 & 0.256 & 0.613 & 1.024 & 0.933 & 1.124 \\
\hline Smoking history & 0.522 & 0.501 & 1.088 & 0.297 & 1.686 & 0.632 & 4.496 \\
\hline Anxiety & 0.123 & 0.548 & 0.051 & 0.822 & 1.131 & 0.386 & 3.312 \\
\hline Depression & 1.719 & 0.627 & 7.516 & 0.006 & 5.579 & 1.632 & 19.065 \\
\hline Sexual dysfunction & -1.888 & 0.738 & 6.543 & 0.011 & 0.151 & 0.036 & 0.643 \\
\hline Olfactory dysfunction & -1.359 & 0.512 & 7.048 & 0.008 & 0.257 & 0.094 & 0.701 \\
\hline F-UG & -0.615 & 0.466 & 1.736 & 0.188 & 0.541 & 0.217 & 1.349 \\
\hline
\end{tabular}

F-UG, first ultrasonic grading,

Table 7. Results of logistics regression analysis at the last treatment of $\mathrm{L}-\mathrm{Cl}$ and $\mathrm{N}-\mathrm{Cl}$ 


\begin{tabular}{|c|c|c|c|c|c|c|c|}
\hline & \multirow{2}{*}{$\begin{array}{l}\text { Regression } \\
\text { coefficient }\end{array}$} & \multirow{2}{*}{$\begin{array}{l}\text { Standard } \\
\text { error }\end{array}$} & \multirow{2}{*}{$\begin{array}{l}\text { Wald } \\
\text { Value }\end{array}$} & \multirow[t]{2}{*}{$P$ Value } & \multirow[t]{2}{*}{ OR } & \multicolumn{2}{|c|}{$95 \% \mathrm{Cl}^{*}$} \\
\hline & & & & & & lower & upper \\
\hline Age of onset & 0.016 & 0.047 & 0.115 & 0.734 & 1.016 & 0.926 & 1.115 \\
\hline $\begin{array}{l}\text { Age of first } \\
\text { treatment }\end{array}$ & 0.032 & 0.048 & 0.441 & 0.507 & 1.033 & 0.939 & 1.135 \\
\hline Smoking history & 0.556 & 0.505 & 1.211 & 0.271 & 1.743 & 0.648 & 4.691 \\
\hline Hypomnesia & 1.351 & 0.485 & 7.759 & 0.005 & 3.860 & 1.492 & 9.983 \\
\hline $\mathrm{RCP}$ & 0.831 & 0.573 & 2.107 & 0.147 & 2.296 & 0.747 & 7.055 \\
\hline Depression & 0.586 & 0.446 & 1.721 & 0.190 & 1.796 & 0.749 & 4.308 \\
\hline Sexual dysfunction & -1.147 & 0.671 & 2.923 & 0.087 & 0.317 & 0.085 & 1.183 \\
\hline L-UG & 0.016 & 0.447 & 0.001 & 0.971 & 1.016 & 0.423 & 2.440 \\
\hline
\end{tabular}

L-UG, Last ultrasonic grading,

Table 8. Comparison of clinical data and ultrasonic grading between PDD and N-PDD patients 


\begin{tabular}{|c|c|c|c|}
\hline & $\operatorname{PDD}(\mathrm{n}=27)$ & $\mathrm{N}-\mathrm{PDD}(\mathrm{n}=97)$ & OR \\
\hline Gender (Male) & 19 & 61 & 1.402 \\
\hline Smoking history & 17 & 70 & 0.656 \\
\hline Drinking history & 1 & 12 & 0.272 \\
\hline Hyperlipidemia & 6 & 19 & 1.173 \\
\hline Diabetes & 8 & 26 & 1.150 \\
\hline Hypertension & 12 & 35 & 1.417 \\
\hline Bradykinesia & 27 & 97 & NA \\
\hline Tremor & 22 & 85 & 0.621 \\
\hline Rigidity & 20 & 56 & 2.091 \\
\hline Hypomnesis & 22 & 76 & 1.216 \\
\hline $\mathrm{RCP}$ & 15 & 17 & 5.882 \\
\hline Somnipathy & 5 & 37 & 0.369 \\
\hline Anxious & 20 & 71 & 1.046 \\
\hline Depressed & 18 & 75 & 0.587 \\
\hline Nonchalance & 3 & 8 & 1.390 \\
\hline Constipation & 21 & 73 & 1.151 \\
\hline Hyperhidrosis & 0 & 4 & NA \\
\hline Postural hypotension & 11 & 38 & 1.067 \\
\hline Dysuria & 16 & 65 & 0.716 \\
\hline Salivation & 6 & 20 & 1.100 \\
\hline Sexual dysfunction & 1 & 9 & 0.350 \\
\hline Olfactory dysfunction & 16 & 41 & 1.987 \\
\hline Pain & 6 & 29 & 0.670 \\
\hline Spasm & 0 & 0 & NA \\
\hline Numbness & 0 & 6 & NA \\
\hline RLS & 2 & 5 & 1.472 \\
\hline SNH & 16 & 53 & 1.208 \\
\hline
\end{tabular}

Figures 
988 patients were excluded because of ET, MSA, PSP,

Parkinson's syndrome, Vascular Parkinson's, Alzheimer's disease

45 cases were excluded: incomplete clinical history record $(n=15)$. Poor image quality of ultrasound results $(\mathrm{n}=18)$. Follow up interval $<0.5$ years $(\mathrm{n}=12)$
A total of 1540 patients were inquired (From April 2019 to April 2021)

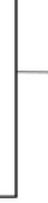

Hospitalized with Parkinson's disease, PD patients $n=552$ at least twice $n=217$

The first and last hospitalized records, ultrasonic images and reports of 172

PD patients were collected

335 cases with only one hospitalization history were excluded

172 PD patients were included in the final study

\section{Figure 1}

Patient flowchart. Exclusion criteria and inclusion process. PD, Parkinson's Disease. ET, essential tremor. PSP, progressive supranuclear palsy. MSA, multiple system atrophy. 


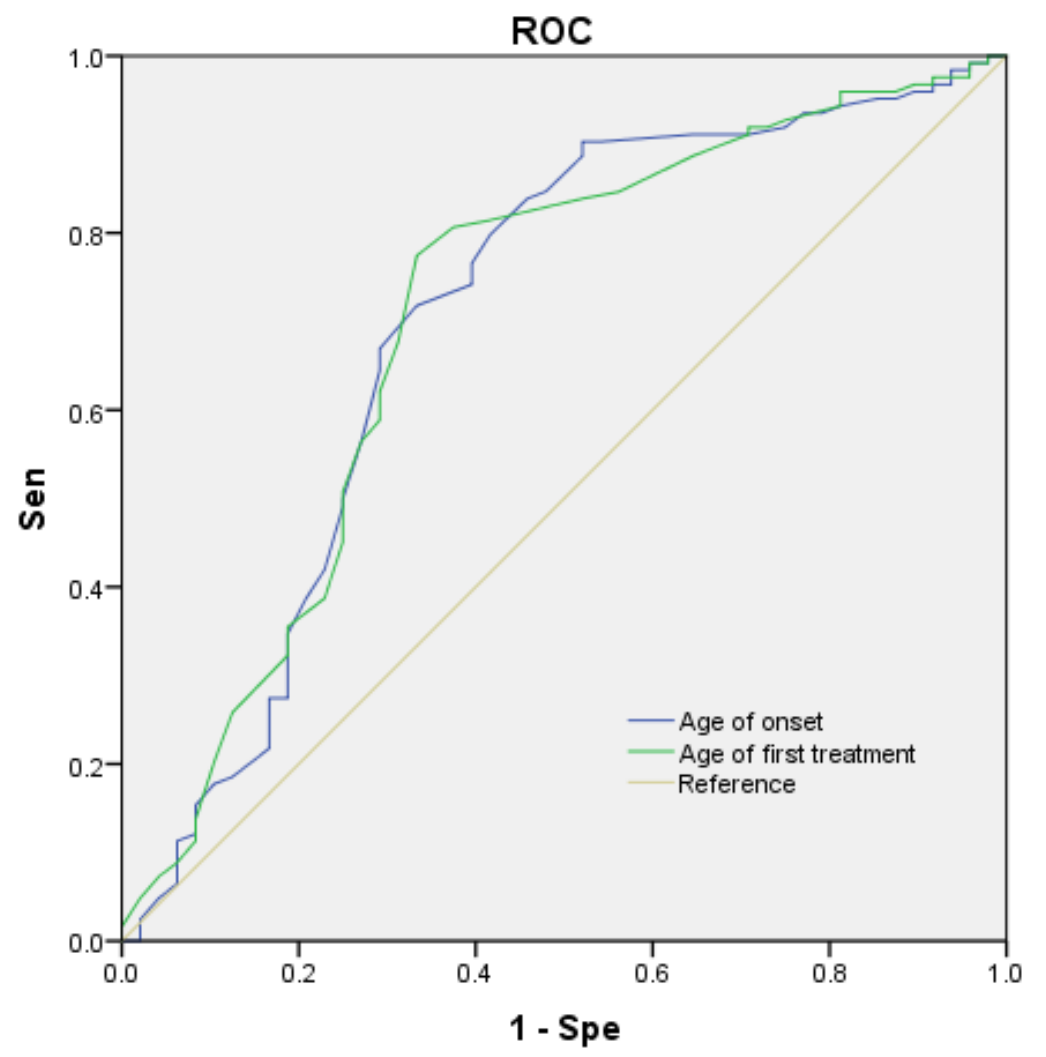

对角段由纬定值生成。

\section{Figure 2}

ROC curve of $\mathrm{N}-\mathrm{Cl}$ and $\mathrm{Cl}(\mathrm{F}-\mathrm{Cl}$ and $\mathrm{L}-\mathrm{Cl})$. The area under ROC curve (AUC) of age of onset and age of first treatment were $0.702(95 \% \mathrm{Cl}: 0.606-0.798)$ and $0.704(95 \% \mathrm{Cl}: 0.610-0.798)$, respectively.
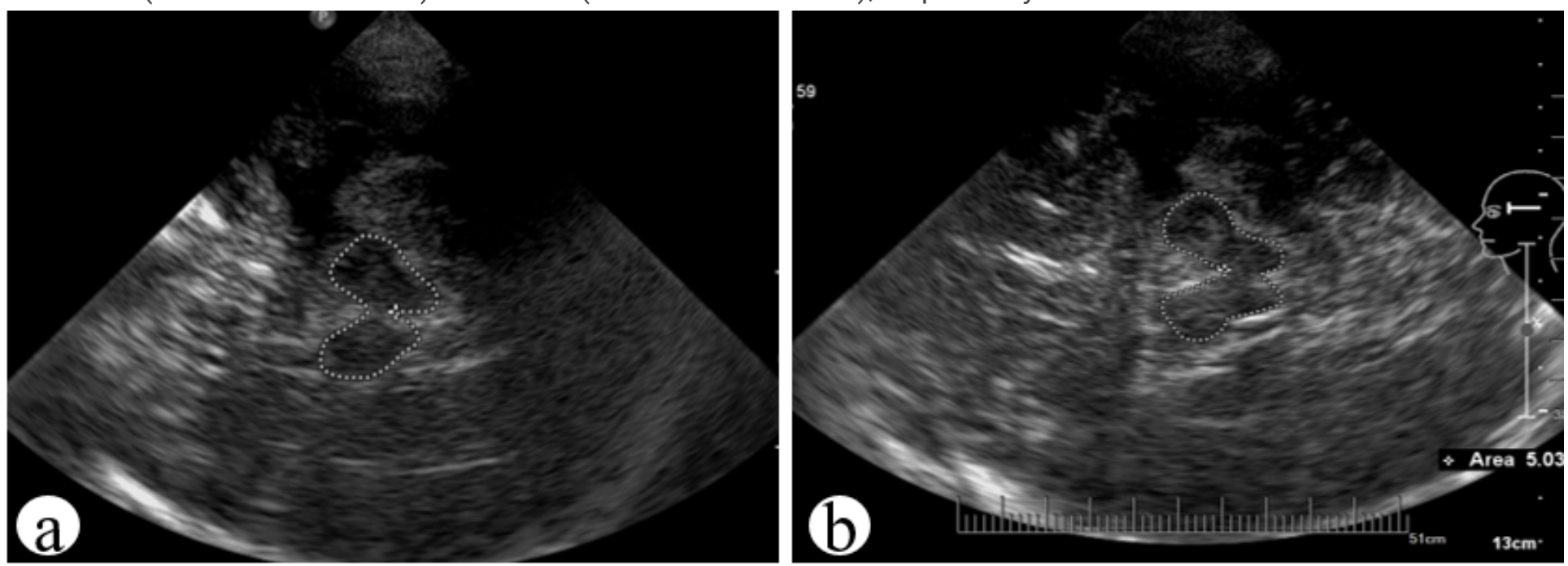

\section{Figure 3}

Male, 65 years old. a. Midbrain area was $4.99 \mathrm{~cm} 2$ and SN grading 2 at the first treatment, b. After 3 years, the symptoms of rigidity and resting tremor worsened, and there is a decrease in calculation and memory. When 
hospitalized again, the midbrain area was $5.03 \mathrm{~cm} 2$ and the $\mathrm{SN}$ grading was 3 , At the last discharge diagnosis, the patient had cognitive impairment.

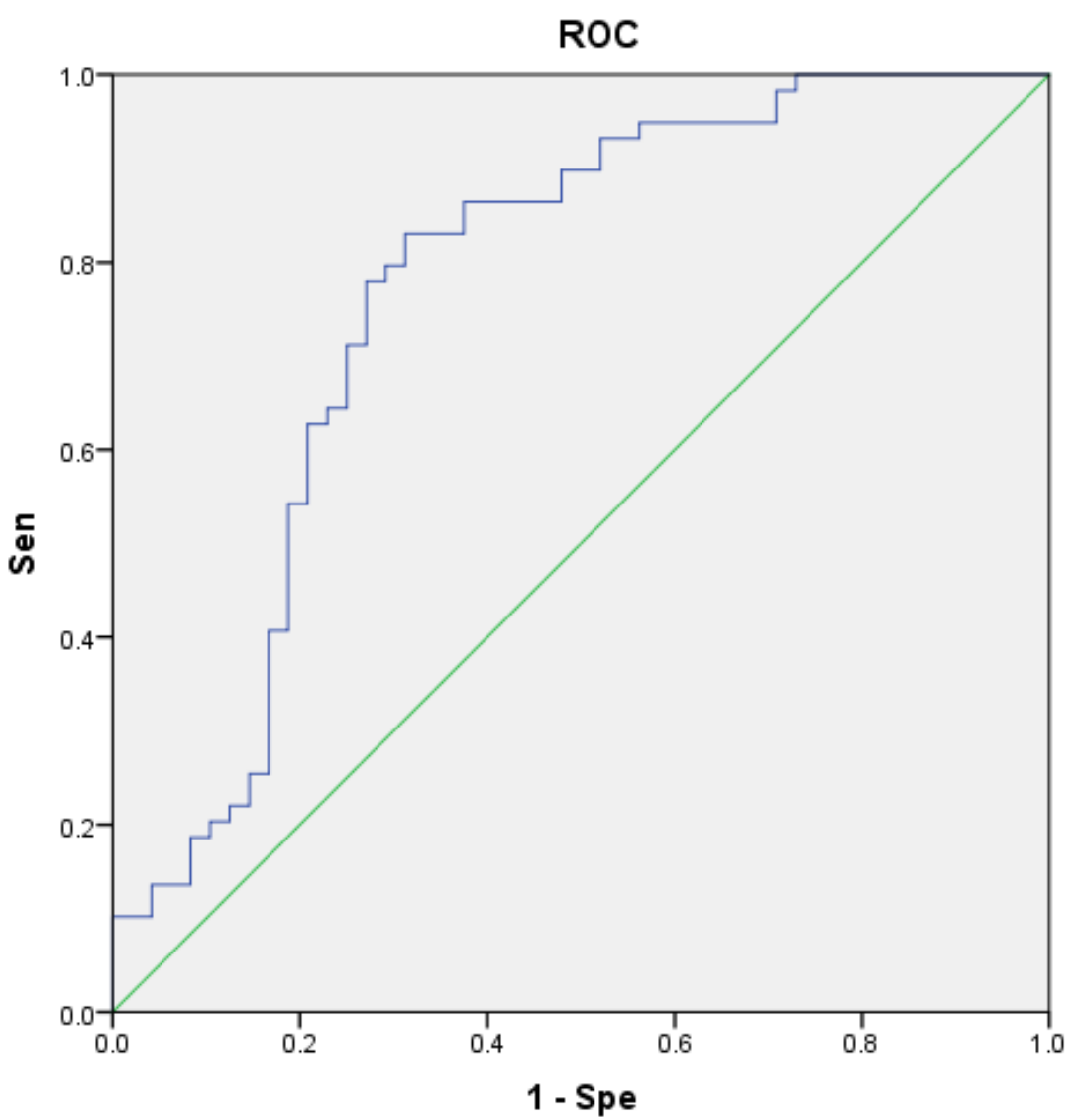

Figure 4

ROC obtained by clinical and demographic logistics regression analysis of $\mathrm{F}-\mathrm{Cl}$ and $\mathrm{N}-\mathrm{Cl} . \mathrm{AUC}=0.770(95 \% \mathrm{Cl}$ : $0.675-$ $0.865)$ 


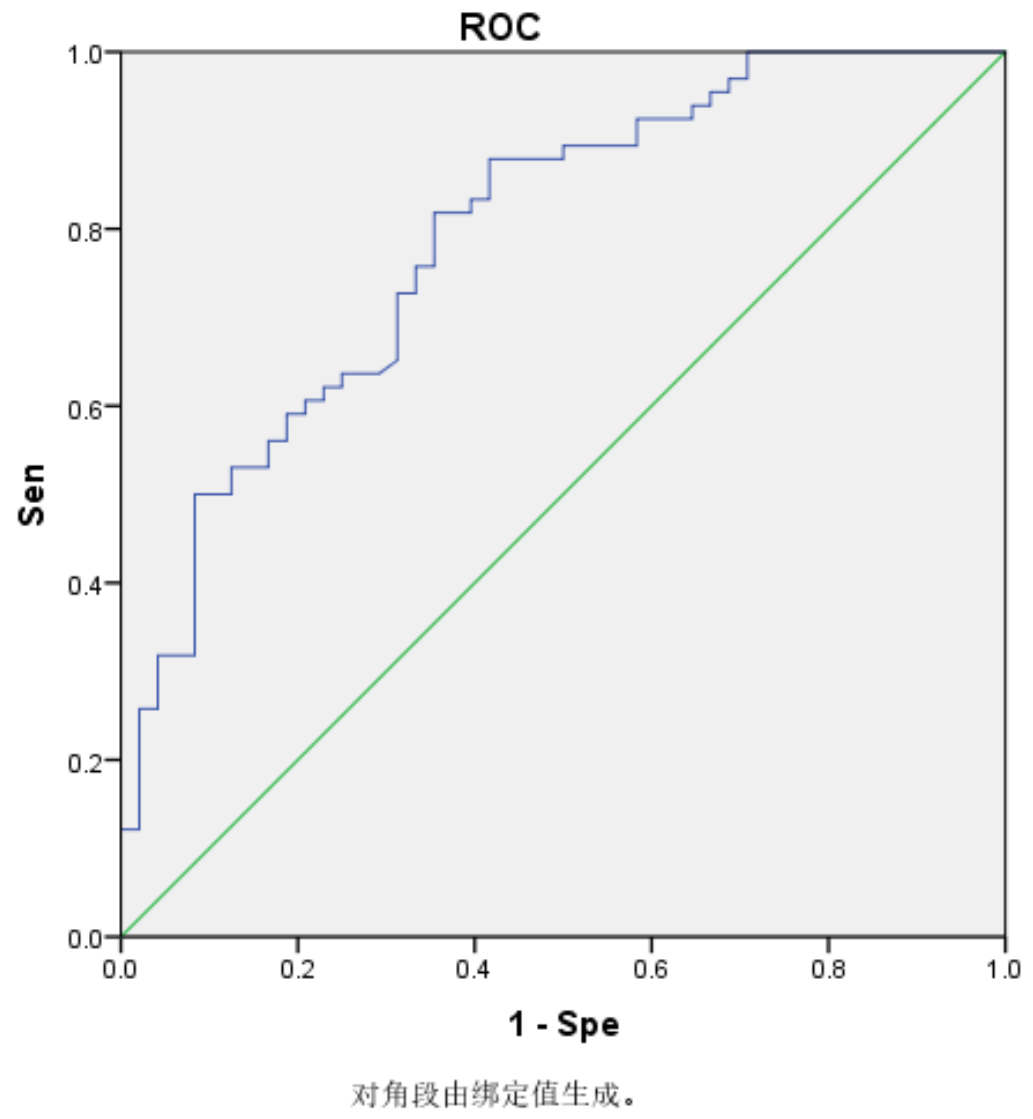

\section{Figure 5}

ROC obtained by clinical, demographic and ultrasonic grading logistics regression analysis of L-Cl and $\mathrm{N}-\mathrm{Cl}$ at the first treatment. $A U C=0.793(95 \% \mathrm{Cl} 0.710-0.875)$. 


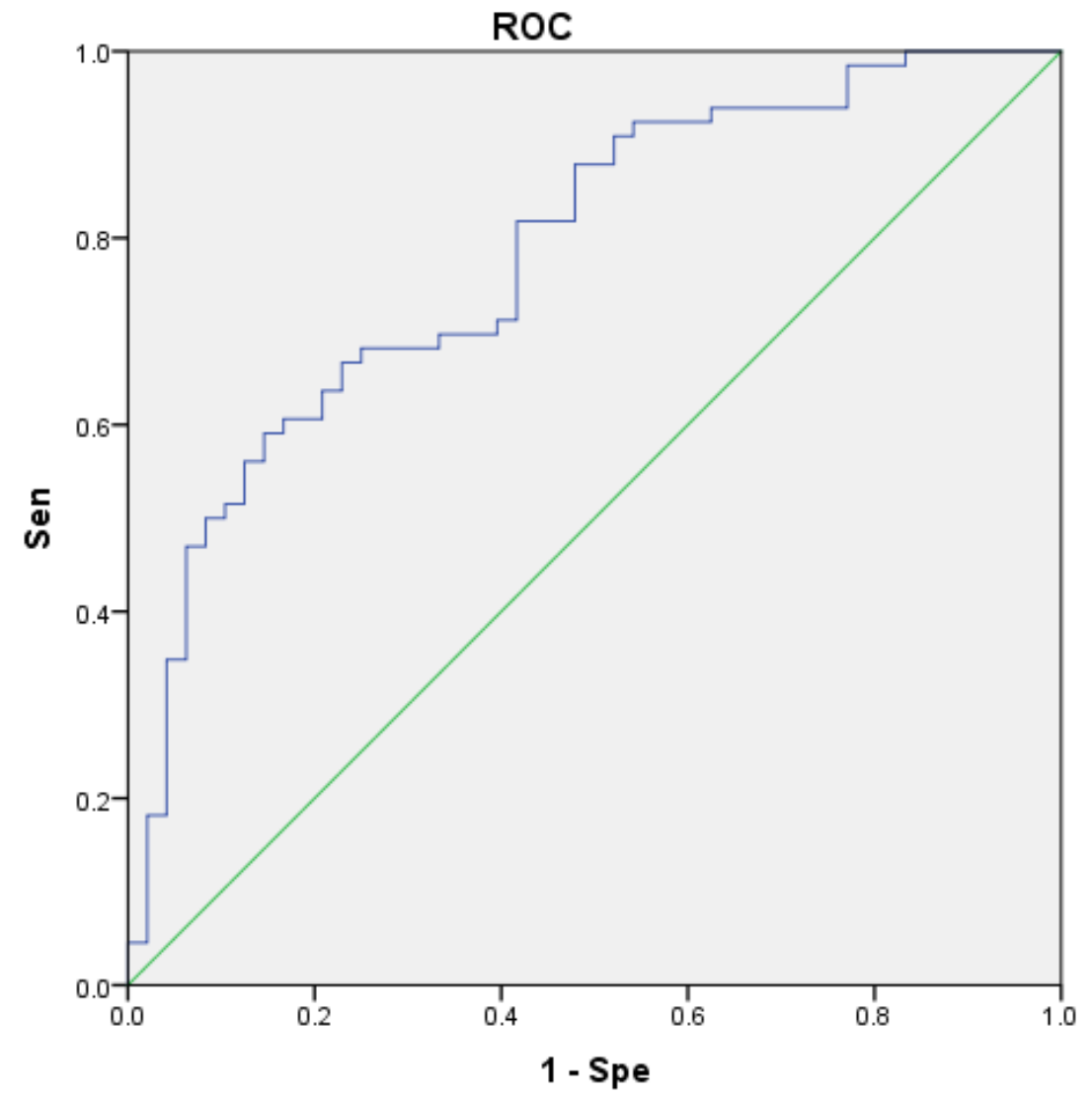

Figure 6

ROC obtained by clinical, demographic, and ultrasound grading logistics regression analysis of $\mathrm{L}-\mathrm{Cl}$ and $\mathrm{N}-\mathrm{Cl}$ at the last treatment. AUC=0.783 (95\%Cl: 0.699-0.868). 